đoán kết cục chức năng tại thời điểm 1 tháng sau khởi phát của bệnh nhẩn XHDN do võ phình mạch não, điểm cut-off có ý nghĩa là 2.5.

\section{TÀI LIÊU THAM KHẢO}

1. (1988). Report of World Federation of Neurological Surgeons Committee on a Universal Subarachnoid Hemorrhage Grading Scale. J Neurosurg, 68(6).

2. Surgical Risk as Related to Time of Intervention in the Repair of Intracranial Aneurysms in: Journal of Neurosurgery Volume 28 Issue 1 (1968). $<$ https://thejns.org/view/journals/j- neurosurg/28/1/article-p14.xml>,

accessed: 23/12/2020.

3. van Heuven A.W., Dorhout Mees S.M., Algra A. và công sứ. (2008). Validation of a prognostic subarachnoid hemorrhage grading scale derived directly from the Glasgow Coma Scale. Stroke, 39(4), 1347-1348.

4. Helbok R., Kurtz P., Vibbert M. và cộng sự. (2013). Early neurological deterioration after subarachnoid haemorrhage: risk factors and impact on outcome. J Neurol Neurosurg Psychiatry, 84(3), 266-270.

\title{
TUÂN THỦ ĐIỀU TRI ARV TRÊN BÊNHH NHÂN HIV CÓĐIỀU TRI NGHIỆN CHẤT DẠNG THUỐC PHIÊ̂N BẰNG BUPRENOPHINE/NALOXONE Ở HÀ NộI
}

\author{
Đinh Thị Thanh Thúy ${ }^{1}$, Vũ Minh Anh ${ }^{1}$, Trần Hữu Bình ${ }^{1}$, \\ Todd Korthuis ${ }^{2}$, Phạm Phương Mai' ${ }^{1}$, Lê Minh Giang1
}

TÓM TẮT

Mục tiêu: Mô tả tỷ lệ tuân thủ điều trị ARV và một số yếu tố liên quan trển nhóm bênh nhân điêu trị nghiện chất dạng thuốc phiện (CDTP̉) và điều trị ARV. Phướng pháp: Nghiên cứu can thiêp không có nhóm chứng tại 4 cơ sở điều trị HIV ngoại trú tại Hà Nội từ năm 2016 đến 2019. Tuyển chọn được 136 đối tượng tham gia và theo dõi trong vòng 12 tháng. Tuân thủ điều trị ARV được đo lường bằng thang đoVAS. Phân tích hỗn hợp (mixed-effect model) để xác định các yếu tố liên quan đến tuân thủ điều trị ARV. Kết quả: $96,3 \%$ người tham gia là nam giới với độ tuổi trung bình là $38 \pm 5,8$ tuổi, $43 \%$ có việc làm, $53,7 \%$ có thời gian sử dụng ma túy trên 10 nẳm và $\mathrm{CD} 4$ trung bình là $411 \pm 216 \mathrm{~TB} / \mathrm{mm}^{3}$.Tự ước tính từ $90 \%$ trở lên uống thuốc ARV đúng giờ trong vòng 7 ngày qua qua là $80,6 \%$ tại thời điểm ban đâu, $87 \%$ tại thời điểm 6 tháng và $79,4 \%$ tai thời điểm 12 tháng. Các yếu tố liên quan đến tuân thủ điều trị cho thấy dương tính với morphine ( $\mathrm{OR}=0.24 ; 95 \% \mathrm{KTC}$ : 0.06-0.90), tải lượng vi rút $\mathrm{HIV} \geq 200$ bản sao/mL $(\mathrm{OR}=0.07 ; 95 \%$ KTC: 0.02-0.28) vàtình trạng điêu trị ARV sau khi tham gia nghiên cứu (OR=0,28; 95\%KTC: 0,08 $0,96)$ thì tuân thủ điêuu trị ARV kém hơn. Kết luận: Tỷ lệ đạt ngưỡng tuân thủ điêu trị ARV tương đối tốt sau 12 tháng theo dõi trong nhóm bệnh nhân nhận điêu trị lồng ghép ARV và điều trị nghiện CDTP bằng buprenorphine.

Tư khóa: tuân thủ điều trị ARV, lồng ghép điều trì nghiện chất và điều trị HIV

\footnotetext{
${ }^{1}$ Trường Đại học Y Hà Nội

${ }^{2}$ Trường Đại học Khoa học và Sức khỏe Oregon-Hoa Kỳ Chịu trách nhiệm chính: Đinh Thị Thanh Thúy

Email: dinhthuy@hmu.edu.vn

Ngày nhận bài: 16.11 .2020

Ngày phản biên khoa hoc: 25.12.2020

Ngày duyệt bài: 4.01.2021
}

\section{SUMMARY \\ ARV ADHERENCE AMONG HIV PATIENTS RECEIVING BUPRENORPHINE/NALOXONE TREATMENT IN HANOI}

Aim:This article aims to describe the ARV adherence rate and associated factors in this population. Methods:Conducting quasi-experimental design (no controlled group) at 4 outpatient HIV clinics in Hanoi between 2016 and 2019, 136 participants and followed up within 12 months. ARV adherence was measured by VAS (visual analogue scale). Mixed-effect model was applied to identify factors associated with ARV adherence. Results: $96.3 \%$ of participants were male with mean age $38,8 \pm 5,8$ years, $43 \%$ were employed, $53,7 \%$ used heroin over 10 years and mean CD4 count was $411 \pm 216 \mathrm{~TB} / \mathrm{mm}^{3}$. Self-reported timely ARV pills taking from $90 \%$ or more in the last 7 days is $80.6 \%$ at baseline, $87 \%$ at 6 months and $79.4 \%$ at 12 months. Findings from the mixed-effect model analysis showed that having positive with morphine in the urine test $(\mathrm{OR}=0.24 ; 95 \%$ KTC: $0.06-0.90)$ and HIV viral load $\geq 200$ copies/mL(OR=0.07; 95\% KTC: $0.02-$ 0.28 ) and receiving ARV treatment after participating in the study (OR=0,28; 95\%KTC: $0,08-0,96)$ lead to poor adherence to ARV medication. Conclusion: The percentage of optimal ARV adherence after 12 month follow is relative good among patients receiving both ARV and buprenorphine treatment.

Keywords: ARV adherence, integration buprenorphine/naloxone and HIV treatment,

\section{I. ĐĂT VẤN ĐỀ}

Tiêm chích ma túy là hình thái lây nhiễm HIV chủ yếu trên toàn cầu, tỷ lệ hiện nhiễm HIV trong nhóm tiêm chích ma túy toàn cầu là 12,6\% [1] và tại Việt Nam là $12,78 \%$ [2]. Tiêm chích ma túy tác động tiêu cực đối với tiếp cận và điều 
trị HIV như tiếp cận điều trị muộn, giảm tuân thủ và duy trì điều trị ART và tăng tỳ lệ tử vong [3]. Lồng ghép điều trị nghiện chất dạng thuốc phiện (CDTP) bằng thuốc thay thế như methadone hay buprenorphine góp phần cải thiện tiếp cận, kết quả điều trị HIVvà giảm tỷ lệ tử vong trong nhóm [3]. Buprenorphine với ưu thế như ít tương tác thuốc với $A R V$, nguy cơ quá liều thấp và thời gian uống linh hoạt đã được sử dụng điều trị lồng ghép tại cơ sở y tế như chăm sóc sức khỏe ban đầu và cơ sở điều trị HIV [4]

Tại Việt Nam, chương trình điều trị nghiện CDTP bằng Methadone đã được triển khai ở Việt Nam từ năm 2008. Chủ trương lồng ghép điều trị nghiện chất và điều trị ARV đã được triển khai với mô hình lồng ghép như cùng địa điểm cùng đội ngũ cán bộ y tế, cùng cán bộ y tế nhưng khác đia điểm hoăc cùng đia điểm nhưng khác cán bộ y tế [5]. Với mụctiêu đánh giá và mở rộng mô hình điêu trị, chúng tôi thực hiện nghiên cứu lồng ghép điều trị nghiện CDTP bằng buprenorphine vào cơ sở điều trị HIV ngoại trú trên nhóm bệnh nhân nhiễm HIV nghiện các chất ma túy dạng thuốc phiện tại Hà Nội từ 2016-2019. Bài viết này nhằm mô tả tỷ lệ tuân thủ điều trị $A R V$ và một số yếu tố liên quan trên nhóm bệnh nhân này.

\section{II. ĐỐl TƯỢNG VÀ PHƯƠNG PHÁP NGHIÊN CỨU \\ 1. Đia điểm và thời gian nghiên cứu.} Nghiên cứu triển khai tại 4 phòng khám HIV ngoại trú tại Hà Nội: quận Đống Đa, quận Hoàng Mai, quận Nam Từ Liêm và quận Long Biên.

Thời gian nghiên cứu: 9/2016 đến hết tháng 9/2019.

2. Thiết kế nghiên cứu. Nghiên cứu sử dụng thiết kế nghiên cứu can thiệp không có nhóm chứng. Lồng ghép điều trị nghiện chất dạng thuốc phiện sử dụng biệt dược Suboxone $\AA$ (Reckitt Benckiser) là thuốc kết hợp buprenorphine và naloxone theo tỷ lệ 4:1 kết hợp với điều trị ART tại cơ sở điều trị HIV ngoại trú.

3. Đối tượng nghiên cứu. Nghiên cứu thu nhận đối tượng là người nhiễm HIV có nghiện chẩt dang thuốc phiên. Các bệnh nhân được lựa chọn đáp ứng các tiểu chí sau: 1) Từ 18 tuổi trở lên; 2) Được chuẩn đoán nghiện chất dạng thuốc phiện theo phân loại quốc tế bệnh học thần kinh (DSM V), và xét nghiệm nước tiểu dương tính với CDTP tại thời điểm đằng kí tham gia nghiên cứu; 3) Mong muốn được điều trị nghiện chất.

Nghiên cứu đã tuyển chọn được 136 bệnh nhân đủ điều kiện tham gia vào nghiên cứu.

4. Kỹ thuật và công cự thu thập thông tin. Đối tượng nghiên cứu được theo dõi trong thời gian 12 tháng và thông tin được thu thập qua phỏng vấn trực tiếp sử dụng bảng hỏi tại 3 thời điểm: ban đầu, 6 tháng, và 12 tháng tham gia nghiên cứu.Đo lường tuân thủ điều trị ARV sử dụng thang đo VAS (visual analogue scale) tự đánh giá tuân thủ điều trị $A R V$ và tình trạng quên liều trong 7 ngày qua. Thông tin về đặc điểm nhân khẩu xã họi, thông tin về hỗ trợ xã hội (sử dụng thang đo MSPSS), vấn đề trầm cảm (sử dụng một phần thang đo DASS-21), kỳ thị với sử dụng chất, và tình trạng HIV được thu thập thông qua phỏng vấn trực tiếp sử dụng bộ câu hỏi cấu trúc. Đối tượng nghiên cứu được lấy mẫu máu để xét nghiệm CD4 và tải lượng vi rút HIV.

5. Xử lý và phân tích số liệu. Số liệu được xử lý bằng phần mềm Stata/MP 14.0. Thống kê mô tả được sử dụng để phân tích thông tin về đặc điểm nhân khẩu xã hội học của đối tượng tham gia nghiên cứu tại thời điểm ban đầu. Để xác định các yếu tố liên quan đến tuân thủ điều trị ART, chúng tôi xây dựng mô hình phân tích hồi qui logistic hỗn hợp (mixed-effect model) để mô hình hóa biến nhị phân là kết quả tuân thủ điều trị và đánh giá tương quan giữa các cá thể là do phép đo lặp lại theo thời gian. Sau khi phân tích mô hình đợn biến, các biến có mức tương quan $p<0.2$ sẽ được đưa vào mô hình đa biến và các biến được xác đinh có mối liên quan đến hiệu quả điều trị từ tổng quan tài liệu được đưa vào mô hình phân tích.

6. Đạo đức nghiên cứu. Nghiên cứu được Hội đồng xét duyệ̂t các nghiên cứu $Y$ sinh học của Trường Đại học $Y$ Hà Nội thông qua theo chứng nhận chấp thuận số 134 ngày 29/10/2013. Đối tượng tham gia nghiên cứu hoàn toàn tự nguyện và không thu thập các thông tin định danh.

\section{KẾT QUẢ NGHIÊN CỨU}

\section{1. Đặc điểm của đối tượng nghiên cứu}

Bảng 1 mô tả một số đặc điểm về nhân khẩu học, kinh tế và xã hội của đối tượng tham gia nghiên cứu. Độ tuổi trung bình của đối tượng tham gia nghiên cứu là $38 \pm 5,8$ tuổi, chủ yếu là nam giới $(96,3 \%)$, và $52,9 \%$ chưa học hết Trung học phổ thông, 44,1\% đối tượng nghiên cứu chưa từng kết hôn và $43,4 \%$ có việc làm. Thời gian sử dụng heroin phần lớn dao động từ 5 năm đến trên 10 năm, trong đó $53,7 \%$ có thời gian sử dụng trên 10 năm. Điểm kỳ thị liên quan đến vấn đề sử dụng chất trung bình là $2,0 \pm 0,7$ và điểm về sự hỗ trợ của xã hội là $3,9 \pm 0,7$. Bệnh nhân có nguy cơ gặp vấn đề về trầm cảm từ mức độ vừa trở lên chiếm $31,6 \%$. Thời gian 
phát hiện tình trạng nhiễm HIV trung bình là $7,5 \pm 5,5$ năm và mức CD4 thời điểm ban đâu trung bình là $411 \pm 216 \mathrm{~TB} / \mathrm{mm}^{3}$. Tỷ lệ đạt ức chế tải lượng virus HIV dưới 200 bản sao/mL máu tại thời điểm theo dõi 12 là 81,8\%. Có 78,4\% bệnh nhân tham gia điêu trị ARV trước khi tham gia vào nghiên cứu.

Bảng 1: Đăc điểm nhân khẩu học xã hội

\begin{tabular}{|c|c|c|}
\hline Đăc điếm & $N=136$ & $\%$ \\
\hline Tuối (Mean, SD) & $38,0 \pm 5,8$ & \\
\hline $\begin{array}{ll}\text { Giới: } & \text { Nam } \\
\text { Nữ }\end{array}$ & $\begin{array}{c}131 \\
5\end{array}$ & $\begin{array}{c}96,3 \\
3,7\end{array}$ \\
\hline Trình độ học vấn & & \\
\hline Dưới trung học phổ thông & 72 & 52,9 \\
\hline Từ Trung học phổ thông trở lến & 59 & 43,4 \\
\hline Cao đằng/Đại học & 5 & 3,7 \\
\hline Tình trạng hốn nhân & & \\
\hline Độc thân & 60 & 44,1 \\
\hline Kết hôn & 50 & 36,8 \\
\hline Ly dị/Ly thân/Góa & 26 & 19,1 \\
\hline Cống việc hiện tại & & \\
\hline Có & 59 & 43,4 \\
\hline Không & 77 & 56,6 \\
\hline Tống số năm sử dụng heroin & & \\
\hline$<5$ năm & 11 & 8,1 \\
\hline 5-10 năm & 52 & 38,2 \\
\hline$>10$ năm & 73 & 53,7 \\
\hline $\begin{array}{c}\text { Kỳ thị liên quan sử dụng } \\
\text { chất (Mean, SD) }\end{array}$ & $2,0 \pm 0,7$ & \\
\hline $\begin{array}{l}\text { Hô trợ của xã hội (Mean, } \\
\text { SD) }\end{array}$ & $3,9 \pm 0,7$ & \\
\hline $\begin{array}{l}\text { Nguy cơ sức khỏe tâm } \\
\text { thân - trâm cảm } \\
\text { Mức độ bình thường và nhẹ }\end{array}$ & 93 & 68,4 \\
\hline
\end{tabular}

\begin{tabular}{|c|c|c|}
\hline Mức độ vữa và nặng & 43 & 31,6 \\
\hline $\begin{array}{c}\text { Số năm phát hiện HIV } \\
\text { (Mean, SD) }\end{array}$ & $7,5 \pm 5,5$ & \\
\hline $\begin{array}{c}\text { Kết quả xét nghiệm CD4 } \\
\text { (mean) }\end{array}$ & $411 \pm 216$ & \\
\hline $\begin{array}{c}\text { Ưc chế tải lượng virus } \\
\text { HIV(<200 bản sao/mL) } \\
\text { tại 12 tháng (n=88) }\end{array}$ & 72 & 81,8 \\
\hline $\begin{array}{c}\text { Điều trị ARV } \\
\text { Điều trị trước khi tham gia } \\
\text { nghiên cứu } \\
\text { Điều trị sau khi tham gia } \\
\text { nghiên cứu }\end{array}$ & 98 & 78,4 \\
\end{tabular}

2. Tuân thủ điều trị ARV. Sử dụng thang đo VAS tự đánh giá mức độ tuân thủ điều trị ARV 7 ngày qua với ngưỡng tuân thủ $\geq 90 \%$ được xem như là ngưỡng tuân thủ điều. Ngưỡng tuân thủ dựa trên kết quả của một nghiên cứu ở Mỹ cho thấy bênh nhân cân tuân thủ điêu trị từ $90 \%$ trở lên để khống chế tải lượng virus[8]. Tỷ lệ bệnh nhân tự báo cáo uống thuốc đúng thời gian theo thang đo VAS từ $90 \%$ trở lên trong vòng 7 ngày qua là $80,6 \%$ tại thời điểm ban đâu, $87 \%$ tại thời điểm 6 tháng và 79,4\% tại thời điểm 12 tháng.

Liên quan đến vấn đề quên liều ARV trong vòng 7 ngày qua, vẫn còn 39,8\% bệnh nhân tại thời điểm ban đâu, 57,5\% tại thời điểm 6 tháng và $43,1 \%$ tại thời điểm 12 tháng quên ít hơn1 liều/1 lân trong vòng tuân qua. Lân cuối cùng mà bệnh nhân quên liều ARV tập trung chủ yếu trong thời gian hơn 3 tháng trước với tỷ lệ 18,4\% tại thời điểm ban đâu, 30,8\% thời điểm 6 tháng và $22,7 \%$ tại thời điểm 12 tháng.

Bảng 3: Thông tin về tuân thủ điều trị ARV

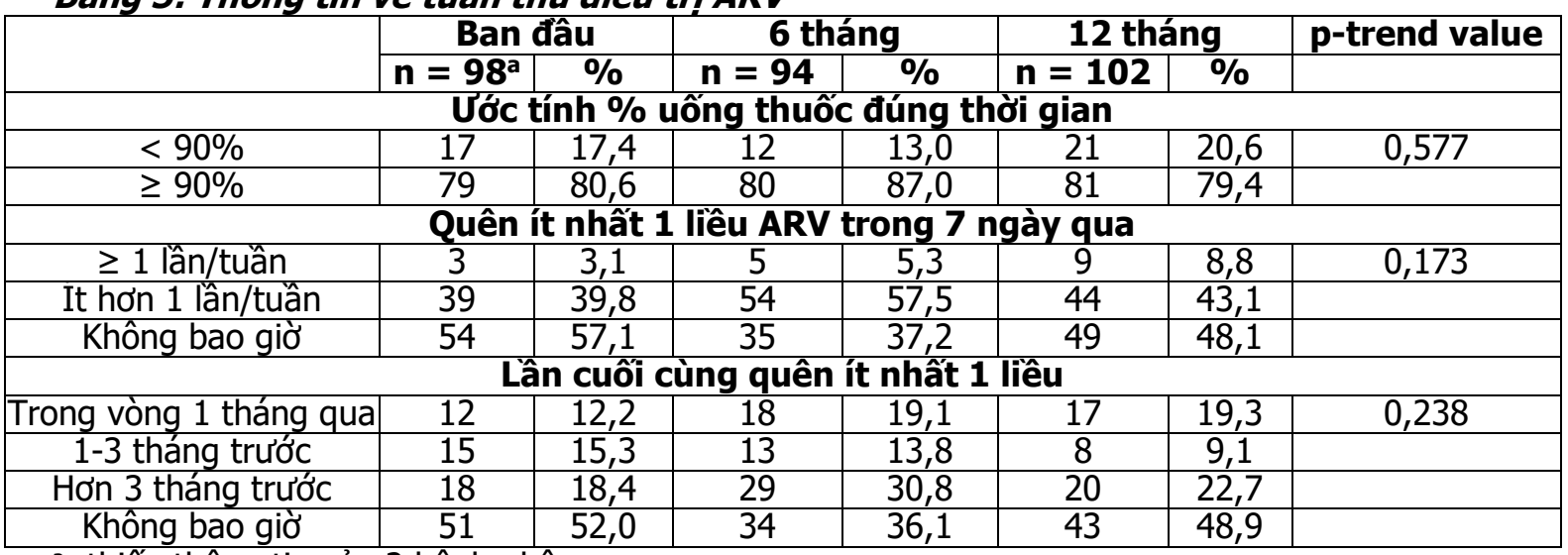

a: thiếu thông tin của 2 bênh nhân

3. Một số yếu tố liên quan đến tuân thủ điều trị ARV. Kết quả phân tích một số yếu tố liên quan đến tuân thủ điều trị ARV từ mô hình phân tích hồi qui logistic hỗn hợp cho thấy các yếu tố như có kết quả dương tính với morphine $(\mathrm{OR}=0,24 ; 95 \% \mathrm{KTC}: 0,06-0,90)$, ức chế tải lượng vi rút $\mathrm{HIV} \geq 200$ bản $\mathrm{sao} / \mathrm{mL} \quad(\mathrm{OR}=0,07$; $95 \%$ KTC: $0,02-0,28)$ và tình trạng điều trị ARV 
sau khi tham gia nghiên cứu $(\mathrm{OR}=0,28$; $95 \%$ KTC: $0,08-0,96$ ) có mối liên quan đến tuân thủ điều trị ARV. Bên cạnh đó, mô hình đơn biến cho thấy những bệnh nhân có việc làm thì mức độ tuân thủ điều trị ART cao hơn 2,20 lần so với nhóm bệnh nhân không có việc làm $(\mathrm{OR}=2,20$; $95 \%$ KTC: 1,16-4,18). Vấn đề kỳ thị với sử dụng chất cho thấy có mối liên hệ ở mô hình đơn biến, bệnh nhân gặp vấn đề kỳ thị càng nhiều thì tuân thủ điều trị càng kém $(\mathrm{OR}=0,99 ; 95 \% \mathrm{KTC}=$ $0,98-0,99)$. Bệnh nhân có mức độ trầm cảm vừa và nặng tuân thủ điều trị $A R T$ kém hơn bệnh nhân mức độ vừa và nhẹ $(\mathrm{OR}=0,35 ; 95 \% \mathrm{KTC}$ : $0,16-0,74)$ ở mô hình đớn biến.

Bảng 4: Các yêu tố liên quan đến tuân thủ điều trị ARV

\begin{tabular}{|c|c|c|c|c|}
\hline & \multicolumn{2}{|c|}{ Mô hình đơn biến } & \multicolumn{2}{|c|}{ Mô hình đa biến } \\
\hline & OR (KTC 95\%) & p-value & aOR (KTC 95\%) & p-value \\
\hline Tuối & $1,02(0,95-1,09)$ & 0,607 & $0,99(0,91-1,08)$ & 0,817 \\
\hline \multicolumn{5}{|c|}{ Tình trạng việc làm } \\
\hline Không & 1 & & 1 & \\
\hline Có & $2,20(1,16-4,18)$ & 0,016 & $1,08(0,43-2,72)$ & 0,865 \\
\hline \multicolumn{5}{|c|}{ Dương tính với morphine } \\
\hline Không & 1 & & 1 & \\
\hline Có & $0,17(0,06-0,51)$ & 0,001 & $0,24(0,06-0,90)$ & 0,034 \\
\hline \multicolumn{5}{|c|}{ Kết quả tải lượng virut } \\
\hline$<200$ copies/mL & 1 & & 1 & \\
\hline$\geq 200$ copies/mL & $0,05(0,02-0,14)$ & $<0,001$ & $0,07(0,02-0,28)$ & $<0,001$ \\
\hline Kỳ thị liên quan sử dụng chất & $0,99(0,98-0,99)$ & 0,005 & $0,99(0,98-1,00)$ & 0,178 \\
\hline Hô trợ của xã hội & $1,02(0,99-1,04)$ & 0,078 & $1,02(0,99-1,05)$ & 0,271 \\
\hline \multicolumn{5}{|c|}{ Nguy cơ sức khỏe tâm thân - trâm cảm } \\
\hline Mức độ bình thường và nhẹ & 1 & & 1 & \\
\hline Mức độ vừa và nặng & $0,35(0,16-0,74)$ & 0,006 & $0,57(0,20-1,60)$ & 0,285 \\
\hline \multicolumn{5}{|c|}{ Điều trị ARV } \\
\hline Trước khi tham gia nghiên cứu & 1 & & 1 & \\
\hline Sau khi tham gia nghiên cứu & $0,05(0,01-0,18)$ & $<0,001$ & $0,28(0,08-0,96)$ & 0,044 \\
\hline
\end{tabular}

\section{BÀN LUÂ̂N}

Tỷ lệ tuân thủ điều trị trong nhóm bệnh nhân ARV điêu trị nghiện CDTP bằng thuốc buprenorphine lần lượt là $80,6 \%$ tại thời điểm ban đầu, 87,0\% tại thời điểm 6 tháng và 79,4\% tại thời điểm 12 tháng. So sánh với nghiên cứu thuần tập theo dõi nhóm bệnh nhân điều trị buprenorphine ở Pháp trong 2,5 năm cho thấy tỷ lệ tuân thủ điều trị là $65,2 \%$ (ngưỡng tuân thủ điều trị là $90 \%$ ) [7] tỷ lệ này thấp hơn kết quả nghiên cứu này. Tỳ lệ tuân thủ điều trị $A R V$ tại thời điểm 12 tháng trong nghiên cứu này cao hơn tỷ lệ tuân thủ điều trị trong một nghiên cứu gộp (meta analysis) tổng hợp kết quả 84 nghiên cứu tai 20 quốc gia cho thấy với ngưỡng tuân thủ $\geq 90 \%$ chỉ có $62 \%$ bệnh nhân tuân thủ điều trị, trong đó nhóm tiêm chích ma túy có tỷ lệ tuân thủ điều trị thấp hơn các nhóm khác [8]. Tỷ lệ tuân thủ điều trị $A R V$ trong nghiên cứu này khá tương đồng với tỷ lệ tuân thủ điều trị ARV của nhóm bệnh nhân HIV tại Hải Phòng, Hà Nội và Hồ Chí Minh có tỷ lệ tuân thủ là $74,1 \%$ với ngưỡng tuân thủ điêu trị $\geq 95 \%$.

Kết quả phân tích một số yếu tố liên quan đến tuân thủ điều trị ARV từ mô hình phân tích hồi qui logistic hỗn hợp (mixed-effect model) cho thấy các yếu tố như có kết quả dương tính với morphine, ức chế tải lượng vi rút HIV $\geq 200$ bản $\mathrm{sao} / \mathrm{mL}$ và tình trạng điêu trị ARV sau khi tham gia nghiên cứu có mối liên quan đến không tuân thủ điều trị ARV. Yếu tố sử dụng ma túy trong quá trình điều trị nghiện có mối tương quan với tình trạng không tuân thủ điều trị ARV tương đồng với kết quả nhiều nghiên cứu trên thế giới. Một nghiên cứu trên nhóm bệnh nhân HIV điều trị methadone cho thấy, hành vi tiêm chích ma túy trong 6 tháng qua trong khi vẫn duy trì điều trị methadone có mối tương quan với không tuân thủ điều trị ARV.

Kết quả từ phân tích mô hình cho thây những bệnh nhân có tỷ lệ ức chế tải lượng virus $\geq 200$ bản $\mathrm{sao} / \mathrm{mL}$ máu thì tuân thủ điểu trị kém hơn bệnh nhân có kết quả ức chế tải lượng virus $<200$ bản sao/mL máu. Phần lớn các nghiên cứu trên thế giới đều cho thấy tuân thủ điều trị giúp khống chễ tải lượng virus, tuy nghiên nghiên cứu của chúng tối cho thấy bệnh nhân có kết quả khống chế tải lượng virus HIV thì tuân thủ điều tri tốt hơn.

Yếu tố tham gia điều trị ARV sau khi tham gia 
vào nghiên cứu thì tuân thủ điều trị kém hơn có thể giả định rằng những bệnh nhân tham gia nghiên cứu của chúng tôi là những bệnh nhân có thể đông cơ điều trị và mức độ sẵn sàng tham gia điều trị chưa cao và có những rào cản trong việc tuân thủ điều trị.

Nghiên cứu của chúng tôi vẫn còn có một số han chế nhất định như các thông tin được thu thập thông qua phỏng vấn trực tiếp, nhiều thông tin được hỏi hồi cứu lại trong khoảng thời gian 6 tháng, điều này có thể dẫn đến sai số báo cáo và sai số nhớ lại. Tuy nhiên, cán bộ nghiên cứu được tâp huấn kỹ về kỹ năng phỏng vấn, khai thác thông tin có thể làm giảm tác động của các sai số trên.

\section{KẾT LUÂN}

Kết quả nghiên cứu cho thây rằng tuân thủ điều trị ARV tương đối tốt trong nhóm bệnh nhân nhận điều trị lồng ghép $A R V$ và điều trị nghiện CDTP bằng buprenorphine. Tuy nhiên, vẩn còn một tỷ lệ nhất định $(20,6 \%)$ chưa đạt ngưỡng tuân thủ điêu trị ARV. Kết quả này đã dẫn đến các khuyến cáo hỗ trợ tuân thủ điều trị ARV như cung cấp liều điều trị nghiện chất phù hợp, thay đổi hành vi sử dụng chất bằng cách kết hợp các liệu pháp tâm lý hành vi. Đồng thời tăng cường các biên pháp hỗ trợ tuân thủ ARV như gửi tin nhắn điện thoại và sự hỗ trợ của gia đình trong quá trình điều trị.
TÀI LIÊU THAM KHẢO

1. UNODC (2020), World Drug Report 2020,

2. Cuc phòng, chống HIV/AIDS (2020), Báo cáo kểt quả phòng, chống HIV/AIDS năm 2019 và nhiệm vụ trọng tâm năm 2020,

3. Low A.J., Mburu G., Welton N.J., et al. (2016). Impact of Opioid Substitution Therapy on Antiretroviral Therapy Outcomes: A Systematic Review and Meta-Analysis. Clin Infect Dis Off Publ Infect Dis Soc Am, 63(8), 1094-1104.

4. Basu S., Smith-Rohrberg D., Bruce R.D., et al. (2006). Models for integrating buprenorphine therapy into the primary HIV care setting. Clin Infect Dis Off Publ Infect Dis Soc Am, 42(5), 716-721.

5. Diep N.B., Korthuis P.T. Trang N.T., et al. (2016). HIV patients' preference for integrated models of addiction and hiv treatment in vietnam. J Subst Abuse Treat, 69, 57-63.

6. Sethi A.K., Celentano D.D., Gange S.J., et al. (2003). Association between adherence to antiretroviral therapy and human immunodeficiency virus drug resistance. Clin Infect Dis Off Publ Infect Dis Soc Am, 37(8), 1112-1118.

7. Moatti J.P., Carrieri M.P., Spire B., et al. (2000). Adherence to HAART in French HIV-infected injecting drug users: the contribution of buprenorphine drug maintenance treatment. The Manif 2000 study group. AIDS Lond Engl, 14(2), 151-155.

8. Ortego C., Huedo-Medina T.B., Llorca J., et al. (2011). Adherence to highly active antiretroviral therapy (HAART): a meta-analysis. AIDS Behav, 15(7), 1381-1396.

9. Tran B.X., Nguyen L.T., Nguyen N.H., et al. (2013). Determinants of antiretroviral treatment adherence among HIV/AIDS patients: a multisite study. Glob Health Action, 6(1), 19570.

\title{
KÊTT QUẢ ĐIỀU TRI GÃY KÍN ĐẦU DƯỚI XƯO'NG QUAY BẰNG NẮN BÓ BộT TẠI BỆNH VIỆN THỐNG NHẤT
}

\author{
Nguyễn Thị Thắm*, Nguyễn Bảo Lục*, Võ Thành Toàn*
}

\section{TÓM TẮT}

Mục tiêu: Đánh giá kết quả điều trị gãy đâu dưới xương quay bằng nắn bó bột tại khoa Chấn thương Chỉnh hình, Bệnh viện Thống Nhất. Phương pháp nghiên cứu: Nghiên cứu tiển cứu mô tả 64 bệnh nhân phát hiện có gãy kín đầu dưới xương quay được điều tri kéo nắn bó bôt và tái khám tai Bênh viển Thống Nhất từ 03/2018 đến 12/2020. Kết quả: Tất cả bệnh nhân được theo dõi và đánh giá sau bó bột 1 tuần, 1 tháng, 3 tháng, 6 tháng trên lâm sàng, 100\% bệnh nhân liển xương, 53,1\% bệnh nhân phục hồi giải

\section{*Bệnh viện Thống Nhất}

Chịu trách nhiệm chính: Võ Thành Toàn

Email: vothanhtoan1990@yahoo.com

Ngày nhân bài: 19.11.2020

Ngày phản biện khoa học: 24.12.2020

Ngày duyệt bài: 5.01.2021 phẫu đạt tốt và rất tốt, 73,5\% bệnh nhân phục hồi chức nắng đạt tốt và rất tốt. Kết luận: Điều trị gãy kín đầu dưới xương quay bằng kéo nắn bó bột vẫn cho hiệu quả điều trị phục hồi giải phẫu và chức năng tốt.

Tư khóa: Gãy kín đầu dưới xương quay; điều trị bảo tồn bằng kéo nắn bó bột.

\section{SUMMARY}

\section{THE TREATMENT RESULTS OF DISTAL RADIUS CLOSED FRACTURE BY REDUCTION AND CASTING AT THONG NHAT HOSPITAL}

Objective: To evaluate the results of the treatment closed fracture of the distal radius by reduction and casting at Thong Nhat Hospital. Methods: The prospective, descriptive study was conducted on 64 patients had closed fractures of the distal radius with reduction and casting at Thong Nhat hospital, from March 2018 to December 2020. Results: All patients were followed after casting at 1 